\title{
Das inquietações ao movimento: \\ um Centro de Atenção Psicossocial (CAPS), a clínica e uma dança
}

Bruna Martins Reis ${ }^{(a)}$

Flávia Liberman ${ }^{(b)}$ Sérgio Resende Carvalho(c)

\section{Uma entrada}

\begin{abstract}
“Várias dança. Dava as mãos. Apresentava cada um o seu nome, tinha as dança homem com homem, mulher com mulher, mulher com homem, homem com mulher. E outras coisas, sem preconceito. E sem abuso de qualquer espécie.

Agilizar o corpo. Movimentar o corpo. De acordo com o que podia, né? Encostava na parede e ia esticar a perna assim. Às vezes, até hoje eu faço. Faço dobrar assim embaixo e voltar devagarzinho pra não subir a pressão." (Samuel(d), usuário)
\end{abstract}

Este artigo se propõe a discutir a experiência desenvolvida em um CAPS, abordando, nesse recorte, aspectos do trabalho cotidiano em um Serviço de Saúde Mental, esboçando uma prática que cria, a partir das inquietações, uma estratégia de cuidado de si e do outro a partir da re-invenção da prática clínica permeada pela dança.

Pretende-se levantar algumas questões que não envolvem um conhecimento específico, mas visam ser disparadoras de processos que possam ampliar outros "fazeres" da clínica da Saúde Mental, como processos criativos implicados à vida de quem cuida e de quem é cuidado, buscando dar visibilidade e explicitar um caminho a partir do qual se possa acolher aquilo que nos passa, que nos acontece, nos toca ${ }^{1}$, como movimento para criar modos mais alegres de habitar esses lugares de vida no CAPS ou na vida daqueles que nele vivem, pois perguntamos: quem ocupa por mais tempo esse espaço? Trabalhadores ou usuários? Quem, além do "louco", constrói sua rotina em uma instituição de Saúde Mental?

\section{Pequena cartografia: caminhos da prática}

“Eu tenho muito marcado aquele dia que você levou um CD, do Pink Floyd? Beatles? Ah era Led Zepellin (risos). Os pacientes piraram gritando, empurrando as paredes e todo mundo fazendo a maior força... Então teve muita coisa que aconteceu ali. Eu tenho essa lembrança, de muita vivência, de coisa muito real, muito na pele." (Tainá, psicóloga) (a) Departamento de Pós-Graduação em Artes da Cena, Instituto de Artes, Universidade Estadual de Campinas. Rua Elis Regina, 50, Barão Geraldo. Campinas, SP, Brasil.13083-854. bru_psi@yahoo.com.br (b) Departamento Saúde, Clínica e Instituições, Universidade Federal de São Paulo. Santos, SP, Brasil. toflavia.liberman@ gmail.com

(c) Departamento de Saúde Coletiva, Faculdade de Ciências Médicas, Universidade Estadual de Campinas. Campinas, SP, Brasil. sresende@ fcm.unicamp.br

(d) Os nomes utilizados no texto são fictícios mantendo em sigilo a identidade dos participantes da pesquisa. 
No CAPS III Antônio da Costa Santos (CAPS Toninho), na cidade de Campinas - SP, entre os anos de 2009 a 2012, aconteceu uma intervenção grupal que se propunha a explorar a experimentação do corpo em movimento. Esta intervenção foi conduzida pela psicóloga, dançarina e coautora deste texto, membro da equipe daquele serviço, como parte do seu cotidiano de trabalho que incluía diversas ofertas, entre as quais: atividades expressivas e terapêuticas nomeadas como oficinas, ateliês e grupos terapêuticos.

Estes encontros foram realizados semanalmente, durante dois anos, com duração de uma hora e meia, abertos a todos os usuários. Passaram pela oficina: profissionais, residentes e estagiários, como participantes ou como cocondutores da prática.

Propunham-se diversas possibilidades de exploração de movimentos dançados a partir de dinâmicas com: exercícios direcionados, jogos relacionais, momentos de improvisação, relaxamento, entre outros procedimentos comuns à linguagem da dança contemporânea, com atenção às singularidades dos corpos, buscando acessar suas possibilidades em um espaço inter-relacional.

Participaram desta proposta quarenta usuários, sendo que, em média, o grupo contava com oito a dez participantes por encontro. Destes, doze usuários mantiveram uma frequência regular ao longo do processo.

Pela percepção de algumas das ressonâncias desta proposta, afirmando o seu caráter transdisciplinar, instaurou-se um processo de pesquisa como parte de um projeto de mestrado ${ }^{(e)}$, com o objetivo de acompanhar esta experiência. Foram criados dois instrumentos de registro do processo: um diário coletivo nomeado pelo grupo como "Diário de Bordo", redigido semanalmente pelos usuários participantes da oficina, para registrar sensações, impressões, desejos, memórias, utilizando diferentes possibilidades expressivas, como desenhos e palavras desconexas que surgiam em alguns momentos do trabalho; um outro diário, nomeado de Diário de Implicação, que foi utilizado para registro das condutoras da oficina, no qual foram impressas sistematizações dos exercícios propostos, além de sensações, percepções, inquietações da pesquisadora ${ }^{(f)}$.

Os diários se configuram como importantes dispositivos na construção da cartografia dessa experiência, por acessarem materialidades das coisas vividas e dos inomináveis processos que se abrem nessas danças. A partir deles, buscamos tatear as linhas que imprimem sentidos ao processo, pois configurava-se aí um desejo: cartografar zonas de criação de intensidades ${ }^{(g)}$ no encontro de corpos em estados de fronteira ${ }^{(h)}$.

\section{Um salto: por uma clínica da reexistência}

Para que se possam conceber serviços de Saúde implicados na reinvenção da vida, faz-se necessário a (re)invenção cotidiana da clínica engajada nessa produção de vida. Para isto, é interessante pensar os usuários da rede de saúde mental como "nômades", como pessoas que, ao se deslocarem no território sócio, geográfico, existencial, produzem redes de conexões não previstas e desconhecidas no mundo do cuidado, exigindo o deslocamento dos equipamentos de saúde para produzir redes, desterritorializadas, que acompanhem este caminhar "nômade" 5 .

Intuição, acaso, improvisação e composição comparecem, neste processo, como elementos importantes para a produção de sensibilidades que contribuam para um cuidado da vida em sua potência.

Essa reinvenção se realiza entre tensões que atravessam o trabalho dentro de uma instituição de saúde. Podemos dizer que, mesmo em ambientes que (e) Pesquisa desenvolvida entre os anos de 2012 a 2014, no programa de Pós- Graduação em Saúde Coletiva da FCM/ UNICAMP, intitulada

"Corpo Fronteira: clínica, dança loucura - uma experiência", e segue em desenvolvimento desde 2014 no Programa de Pós-Graduação em Artes da Cena do IA/UNICAMP. Link para acesso à

dissertação: http://www. bibliotecadigital.unicamp $\mathrm{br} /$ document/?code $=000934579$

(f) Todas as narrativas de usuários e profissionais utilizadas neste texto foram retiradas dos diários e de trechos de entrevistas realizadas com alguns participantes da oficina durante a pesquisa de mestrado citada.

(g) Inspirados pela obra da bailarina Pina Baush, podemos dizer que as zonas de criação de intensidade dizem respeito à plasticidade da experiência que encontra outras formas de acomodação a ordem estabelecidade ${ }^{2}$. Para Pina Baush, as cenas criadas são sempre, num primeiro momento, expressão das individualidades e tem como ingredientes sentimentos genuínos, recordações pessoais e exposição da própria fragilidade que fazem da dança-teatro de Pina Bausch uma forma de expressar a vida na sua mais ampla diversidade ${ }^{3}$.

(h) Sobre Fronteira, citamos Ferracini: "Fronteira não é linha. Nem demarcação meramente espacial ou temporal entre dois pontos ou territórios. Não é uma marca de delimitação. Em realidade é também... mas não é, absolutamente, esse o sentido comum-sensocomum-que interessa. Espaço-entre, in-between, MA (Tadashi Endo),

Entre-mundo (Bharbha), Indiscernibilidade (Deleuze), esses são os outros nomes de fronteira que interessam, pois eles não são apenas nomes, mas estados-de-vida-emaberto-e-em-potência. Um espaço, um território de fronteira, é, por excelência, um território de devir"4 (p. 2). 
(i) Segundo Deleuze e Guattari, somos formados por três tipos de linhas: (a) dura (b) maleável e (c) de fuga. As linhas duras nos compõem através do estabelecimento de dualidades sociais, que nos estratificam, no sentido forte do termo. São as grandes divisões na sociedade: rico ou pobre, trabalhador ou vagabundo, normal ou patológico, homem ou mulher, culto ou inculto, branco ou negro, etc. As linhas maleáveis possibilitam variações, ocasionando desestratificações relativas. $\mathrm{E}$ as de fuga representam desestratificações

absolutas, no sentido em que rompem totalmente com os limites das estratificações estabelecidas $^{3}$ (p. 373) nasçam do desejo de novas práticas e concepções de tratamento, como costuma ocorrer nos CAPS, as linhas duras (i) continuam operando na captura do trabalho, podendo, por vezes, cristalizar os trabalhadores em lugares cômodos que acabam despotencializando o olhar, o corpo, os afetos.

A gestão do tempo comparece, neste contexto, como uma das principais estratégias de nossas instituições. Como trabalhadores dos CAPS, somos demandados a dar conta de múltiplas atividades, entre as quais: atendimento individual, tarefas administrativas, diversos grupos que se efetuam em um tempo que, nem sempre, favorece os encontros.

Como, então, criar outras possibilidades afetivas e temporais para vivenciar os encontros entre trabalhadores e usuários em um CAPS? A dança poderia contribuir para a desterritorialização deste modo de operar de nossas instituições?

Provocados por estas questões, buscamos, por meio de uma oficina de dança, constituir um dispositivo que se afirmasse enquanto um contratempo ao ritmo acelerado do CAPS que, em nosso entendimento, se traduzia, às vezes, em demandas inesgotáveis para os trabalhadores e a produção de uma rotina de cuidado esvaziada de sentido para alguns usuários.

Apostamos, naquele momento, que isto seria possível por intermédio da criação de territórios referendados pela intensidade das relações que enfatizariam uma clínica/acontecimento que celebrasse a diferença e possibilitasse as (re) invenções dos sujeitos em relação. Uma clínica que colocasse em questão práticas de cuidado que vigiam para disciplinar e controlar, buscando afirmar um cuidado que liberta ao buscar cuidar do outro, cuidando de si ${ }^{6}$.

A partir das vivências e estudos, entendíamos que tal desterritorialização poderia se efetuar por meio de práticas que mobilizam um modo de dançar pautado por uma concepção que procura romper com padrões estéticos hegemônicos e recoloca as relações, elas mesmas, como obra.

\section{Variando os tempos}

No relaxamento: O CAPS efervescendo e o grupo em silêncio. Um silêncio paradoxal. Percepções de um outro lugar do CAPS no CAPS. (Diário de Implicação)

Qual é o tempo do encontro? Qual o tempo da dança? Que dança se dança?

São questões que movem mundos e redefinem a maneira como procedemos nesta prática que expressa uma coletividade e traz, à tona, as impregnações dos corpos que estiveram presentes em cada encontro/dança.

Em muitos momentos, a oficina de dança foi vivenciada, pelos corpos presentes, como um espaço/tempo alterado, expandido, uma espécie de cadência que foge àquilo que é mais comum ao cotidiano do CAPS.

"A gente sempre estava ali na cozinha, arrumava o refeitório, e a gente escutava e dava uma espiadinha.

E o que eu via aí, era vários usuários que nunca conseguem interagir em outros grupos, ali eles iam. Saíam de lá com uma expressão aliviada. Então eu acho que é uma maneira de colocar eles numa sala fechada, mas de uma maneira mais solta. Que eles não ficavam perdidos, eles gostavam de participar [...]. Do jeito deles lá. Tem usuários que não conseguem falar, mas eles têm uma maneira de expressar, como usam o corpo, eles conseguiam colocar pra fora na dança, com as expressão deles, aquilo que eles estão sentindo. Eu acho que isso é que faz a diferença [...]. Eu via umas coisas bem bonitas pela frestinha da janela, 
não dava pra ver direito mas você não acreditava como era bonito". (Conceição, trabalhadora de apoio do CAPS)

Não seria impreciso dizer que, naquele serviço, há um ritmo de trabalho que, embora seja preenchido por alternâncias de diferentes durações, tem grande acentuação nas frequências rápidas. Ritmo marcado por aquilo que se convencionou como estratégias de tratamento: atendimentos individuais e grupais conduzidos pelas equipes multiprofissionais, compostas, convencionalmente, por psicólogos, psiquiatras, enfermeiros, técnicos de enfermagem, terapeutas ocupacionais (T.O.), entre outros arranjos possíveis. Além da vasta gama de intervenções medicamentosas que tem, em muitas situações, o intuito de: amenizar sintomas, evitar que a loucura brote, manifeste-se, e se apresente também enquanto um tipo de expressão.

Constrói-se, assim, uma clínica pautada na construção de um modo de operar legitimado por um saber/fazer com foco exclusivo na doença, com poucos espaços para o contraditório, o desequilíbrio, a exacerbação pela falta ou pelo transbordamento.

Uma lógica que desafia e coloca em questão o projeto CAPS, que nasce pautado, justamente, pelo objetivo de desconstruir o lugar do tratamento normativo, que tem, como referência principal, a clínica do corpo de órgãos, que desconsidera outras sensibilidades e potencialidades da vida errante do louco. Potencialidades que só podem ser descobertas em uma clínica que se propõe singularizada, aderida a outros modos de conceber a loucura, não apenas como desrazão.

No "olho do furacão"7 dos serviços, nos contentamos, perante a fragilidade da vida dos usuários e sob pressão do tempo institucional, em medicalizar nossos usuários. Apesar de nossos desejos, nem sempre conseguimos sair do ritmo marcado e alçar outros saltos nas melodias conhecidas e institucionalizadas.

Ao colocarmos em questão a temporalidade que marca o encontro com o usuário, não desconhecemos, com isto, a importância e necessidade de compormos propostas mais convencionais. Buscamos destacar, isto sim, a insuficiência destas últimas e a necessidade de assumirmos a importância de um trabalho que se faça nas minúcias de nossos encontros com o corpo-loucura. Uma luta, portanto, contra nossa própria captura de uma concepção manicomial, que insiste em determinar nossas práticas, saberes e corpos.

Neste tempo do "produtivo" do encontro, há pouco espaço para a experimentação, para experiência, para a improvisação sem a busca por um produto final, sem "cura" e sem material "concreto" desta produção. Sendo assim, há sempre "algo" que se espera de cada encontro, algo que medeia a ação, seja a melhora dos sintomas, seja o artesanato que se leva para a casa, seja o aprendizado de alguma nova aptidão útil à reinserção social.

O risco de uma temporalidade instituída e internalizada por cada um de nós, profissionais, é sempre o de entrar na relação com a atividade carregado dos clichês das formas prontas. Reproduzir formas de pensar a relação profissional/usuário, mediadas pelas teorias e técnicas que fazem parte do "cardápio" de atividades que "têm que ter" nos CAPS. Atividades que, quando incorporadas desta forma, podem ser pouco comprometidas com a processualidade de cada um - neste caso, também do profissional e do usuário, pois há sempre um processo em andamento em cada corpo envolvido - e pouco abertas à criação de outros espaços/tempos naquilo que se produz. Ou são, em muitos casos, pouco sintonizadas com um tempo que é o tempo do partilhar, tempo que não pode ser medido no relógio.

Apesar de seus propósitos, os CAPS, ao buscarem compor suas grades de ofertas de serviços, passam a se guiar pela lógica da produtividade ${ }^{8}$, abdicando de seu caráter peripatético ${ }^{5}$ e da produção de um agir micropolítico que se efetue enquanto um trabalho vivo em ato ${ }^{9}$, que tenha como compromisso a afirmação da vida enquanto um eterno ato de (re) criação e acontecimento.

Uma negação que cobra seu preço quando observamos, muitas vezes, na experiência de trabalho no caos do CAPS, cenas cotidianas que Moehlecke refere como

Uma multidão de corpos estremecidos à espera uma consulta marcada, ou clama por um segundo de paciência. Trabalhadores parecem repetir a mesma tarefa, cotidianamente, robotizados por um fazer que devora o próprio movimento. Um sentimento de desdém invade 
o peito. Um súbito mal-estar parece transbordar o juízo. De que modo acompanhar o desatino do outro, sem também perder-se? Como não cair no engodo de, frente à confusão alheia, propor uma rotina esmagadora e policialesca? ${ }^{10}$. (p. 46)

É aqui que, mais do que nunca, se impõe a necessidade de afirmarmos o dever da invenção de falar da criação proposta, por exemplo, pelo grupo de dança, como um contratempo ao ritmo e aos modos instituídos pela instituição, como nos convida Deleuze ${ }^{11}$ :

[...] como traçando seu caminho entre impossibilidades [...] A criação se faz em gargalos de estrangulamento. [...] Se um criador não é agarrado pelo pescoço num conjunto de impossibilidades, não é um criador. Um criador é alguém que cria suas próprias impossibilidades, e ao mesmo tempo cria um possível. (p. 167)

Será, portanto, este estrangulamento, que nos é tão comum e que pode nos acomodar e endurecer, o motor capaz de nos conduzir a estados de criação e invenção de linhas de fuga no cotidiano?

$\mathrm{Na}$ experiência dessa pesquisa, observamos que o desconforto e a inquietação perante alguns estados de corpo, um tanto conformados e atuando num modo de "piloto automático", foram os principais motores para que o serviço viesse a propor estratégias de criação de outros possíveis, de outros arranjos para gerir os encontros em seus espaços. Apostava-se aí que as qualidades de encontros instaurados a partir desses outros modos de se relacionar se afirmariam, acima de tudo, pela potência do que se produziria ali, seria aquilo que se criaria e que cada um carregaria consigo para a vida, seria um experienciar-se para tornar possível, conforme nos sugere Deleuze ${ }^{11}$, outras possibilidades de ser/estar na vida.

Nesse acontecer, nossa pesquisa não teve como intencionalidade avaliar atividades mais interessantes ou mais válidas no CAPS; mas, sim, a de explicitar um meio de fazer e um meio de colocar os problemas que este fazer implica. Interessou-nos abordar este feitio de tocar no contratempo, a quebra, o improviso, no que ele se aproximou ou se distanciou de outras atividades neste serviço. Certamente, existem, em cada célula do espaço CAPS, novos mundos em pequenas rupturas acontecendo. O que nos cabe é tracejar uma forma de proceder a ruptura. Um fazer que escapa, não "o fazer", mas apenas um fazer.

Quais os deslocamentos que este fazer produz na medida em que se dispõe a experimentar o acaso de cada encontro? Detalhamos, a seguir, o sentir/afetar de um corpo pesquisadora/trabalhadora em seu movimento de dar visibilidade à realidade viva deste novo espaço de encontros.

\section{Premissas de uma experiência: a imersão na dança}

A partir da compreensão aqui afirmada, que é, ao mesmo tempo, uma afirmação ética, estética e política, apostamos na prática da dança como um espaço de estar entre, fazer junto, acompanhar de perto o corpo, para desestabilizá-lo e torná-lo mais receptivo aos encontros e às composições não apenas como uma condição dada pela dança, mas como uma premissa da clínica que se almeja construir. Uma clínica do imprevisível, em que o que se faz é habitar uma zona híbrida e descobrir, em suas entranhas, as potencialidades de cada um, seja usuário, seja profissional. Conforme nos dizem Passos e Benevides ${ }^{12}$, trata-se de uma necessidade da clínica: "habitar este espaço intervalar do entredomínios, do que não é totalmente isto ou aquilo, do que está nesta operação da conjunção "e", lá onde proliferam encontros e composições"12 (p. 1).

Nos esforçamos por sustentar essa prática como uma intervenção da clínica que provoca deslocamentos e possibilidades de "pausa" no meio da aceleração, inventando uma outra estratégia de se conectar com a clínica, com o corpo, com a dança e com a Saúde Mental.

O trabalho da clínica busca acompanhar os movimentos afectivos da existência construindo cartas de intensidade, ou cartografias existenciais que registram menos os estados do que os fluxos, menos as formas do que as forças, menos as propriedades de si do que os devires para fora de $\mathrm{si}^{13}$. (p. 3 ) 
Dessa forma, a clínica se faz como técnica de cultivo de si e de encontros que possam aumentar a potência de cada corpo em seguir variando, dando formas renovadas a si mesmo e ao mundo em que cada um se insere. Como um germinar.

No processo do grupo de dança, esse semear se fez a partir de técnicas em dança, nas quais buscava-se um acesso ao corpo presente, sem preocupações estéticas e coreográficas. Nas minúcias de cada dia, lapidavam-se possibilidades expressivas, que acionavam estados de corpo intensificados, de escutas ampliadas, de poros abertos e de encontros despretensiosos compostos por movimentos e pausas.

Um misto em que clínica e dança se afirmam enquanto processos de subjetivação. Fronteira. Lugares paradoxais em que corpo e vida se engendram, cocriam-se, confundem-se. Lugares de cultivo de si, de preparação para que algo brote, germine, cresça em potência de devir.

"Eu me senti muito ótima, gerei-me um pé de jabuticaba, dei muitas folhinhas e frutos, me senti muito bem." (Damiana, usuária)

“Dancei. Eu gostei muito de mim mesmo." (Marcelo, usuário)

Pode-se dizer que os bons encontros prosperaram quando a experiência se tornou algo assimilável, rompendo automatismos e ritmos habituais. Quando se instalaram outros repertórios de movimento e de formas existenciais, mesmo sem que estas pudessem ser nomeadas ou compartilhadas, como mundos que se abrem em silêncio. Naquele invisível do corpo que nos habita e nos transforma.

Deixamos, aqui, algumas sonoridades-mundos expressas em palavras, não como comprovação, mas como provocação, transbordamento e impressões do mapa deste improviso

"A gente fugiu um pouco do diagnóstico, não negando a sintomatologia, mas ver pra além daquele corpo que foi significado num certo diagnóstico, num certo transtorno [...] lembro do Walmir que é um cara psicótico, muito maluco, um corpo travado, podendo experimentar seu corpo de forma diferente, ser respeitado nos seus limites, nas suas potências dentro do grupo. O oposto da Mariana que tinha um outro diagnóstico, uma neurose grave, podendo a partir do grupo ressignificar a própria beleza, o lugar da mulher, suas singularidades, sua vontade de cuidar de si.

[...] mas acho que a cena que ficou mais intensa pra mim, que eu sempre lembro de pensar 'gente como é que podia ser tão diferente', era o Bastião. Bastião morou no leito do CAPS por muito tempo e eu era a referência. Eu tinha dificuldade em administrar a referência de um morador de leito e que não tinha um diagnóstico fechado, viveu em situação de rua, uma história frouxa, de uma mãe que cuidou por um tempo, uma família que abandonou, a gente não sabia se passava por uma deficiência mental, uma psicose, não dava mais pra saber [...] parecia ter setenta anos, tinha 48 na época. Não tinha documento, não tinha nada e a gente foi tentando cuidar dele e o mais difícil é que o comportamento dele era muito agressivo, intempestivo, era difícil de entender porque ele reagia daquela maneira em situações assim... estava andando na grama e de repente pegava uma pedra e jogava, de repente batia num usuário, não dava pra conectar. Seu repertório de fala, de linguagem era muito escasso, corporalmente, e às vezes ele entrava no grupo.

No grupo nunca aconteceu nenhuma situação de agressão, o que acontecia eram gargalhadas, da alma. Ele gargalhava e a gente não sabia muito por onde isso passava na vida dele, a gente perguntava 'ah Bastião o senhor gosta de dançar?' e ele falava que gostava, mas assim, era de uma intensidade pra ele, que contagiava a gente.

A gente conseguia ver um outro Bastião. Um ser humano de verdade, porque fora dali, a equipe tinha uma certa raiva dele, às vezes tinham vontade de expulsá-lo.

Então quando ele entrava no grupo ele também me possibilitava vê-lo de outra forma e aí me ajudava a sustentá-lo [...] porque tinha um outro Bastião ali dentro, que não era só o impulsivo, o agressivo.

Às vezes, ele até passava para algumas pessoas da equipe como o folgado, o que está se aproveitando da situação, o que evidentemente não era, era um senhor que por $\mathrm{N}$ questões da vida não [...] estava ali, viveu na rua, não conseguiu desenvolver um zilhão de habilidades, mas tinha prazer, tinha 
vontade. Tinha desejo, que sorria e dependendo dos movimentos que a gente fazia no grupo, ele se transformava [...] quando a gente imitou os animais [...] a proposta era de experimentar o corpo de uma outra maneira também imitando animais ou imitando o outro e aquilo fazia com que ele caísse na gargalhada e verbalmente ele não conseguia dizer o que estava acontecendo com ele, mas a gente percebia que era prazeroso. Tinha um lugar pra ele muito bom. E ele sustentava a atividade e tentava fazer, era lindo de ver! E acho que era o único espaço onde ele entrava e ficava, seja em atividades, seja em atendimentos em grupo ou individuais, ele nunca sustentava estar em uma sala fechada". (Elise, Terapeuta Ocupacional)

\section{Com tornar cotidiano: atos de criar}

A prática-contratempo do grupo de dança se configura como uma das estratégias de sobrevivência à tendência de todos nós em seguir o ritmo marcado dos compassos fortes, sem variar, em um processo que não é, a priori, bom ou ruim, mas que surge do movimento de resistir, tornando possível um outro tempo/acontecimento no cotidiano do CAPS. Acontecimento que cria marcas e produz algo da ordem do precário nos corpos envolvidos e no campo onde este fazer acontece.

As palavras de Samuel, participante da oficina, trazem-nos uma imagem daquilo que considero a "produção" deste tipo de trabalho implicado em outras temporalidades de vida: "Eu, Samuel, gostei de tudo com alegria e prazer, como quem toma um remédio que cura a alma e o corpo" (Samuel, usuário).

Fazemos, assim, outro posicionamento: a inventividade do trabalho como práticas que se configuram em lutas micropolíticas travadas todos os dias no cotidiano. Em ações simples ou complexas. $\mathrm{Na}$ retomada da capacidade de cada sujeito de perturbar o estado cômodo e cristalizado das ações diárias. No cotidiano de cada vida que segue em fluxo e persevera em existir diferenciando-se.

É nisto que apostamos. Nestes modos de fazer que são ritmo-fluxo-tempo-diferença, que pedem passagem e reverberam. Criam tempo. Contam tempo. Contratempo.

Lembro da atenção e dos participantes se entre olhando quando proponho a dinâmica do silêncio, que consistia em fazer os exercícios sem falar, apenas estar atento e fazer. Eu conduzia os exercícios também com um outro tipo de atenção, quase como se eu também fizesse em silêncio. A princípio nem eu mesma estava certa se funcionaria. Instaura-se um clima de segredo, de algo precioso, quase sagrado. Lembro de muitos olhares de confirmação dirigidos a mim. Alguns inclusive, se sustentando em mim com o olhar. Incrível aquele estado de suspensão da sala. Quando vou para o chão e me calo, deitada ao lado dos participantes, o que percebo é quase inacreditável, estávamos há uma hora se movimentando sem falar. Enquanto isso o CAPS acontecendo a todo vapor, fervilhando, e nós ali, na suspensão do estar presente naquele lugar, naquela hora, naquele encontro. Simples e grande assim. Permanecemos deitados em silêncio absoluto por 15 minutos, quando lentamente me levanto e abro a porta sinalizando o fim. Aguardo em silêncio ao lado da porta e espero cada um se levantar e sair calmamente. Nos despedimos com olhares de muita intensidade. Alguns sorriam. Outros apenas calçavam seus sapatos e saíam. Um ou outro ainda, se permitiu um tchau e obrigada. Mas todos, sem exceção, saíram dali dilatados. Fiquei mais um tempo na porta depois de me despedir e não conseguia conter minha alegria e encanto por tudo o que vivemos naquela pausa, naquele silêncio. Fecho a porta da sala e me deixo rir sozinha de contentamento, me sentindo também dilatada. (Trecho do Diário de Implicação)

Processos criativos no trabalho em saúde que abrem mundos articulam saberes e movem políticas na delicadeza de cada encontro. Instaurando variações. Quebrando a monotonia do ritmo diário. São fazeres entre corpos que criam corpos.

Corpos comprometidos com a criação de outros mundos a cada relação.

Corpos em zonas de fronteira.

Conforme Ferracinit: 
Como vimos, uma fronteira não existe na linha que delimita territórios; ela se constrói e é criada-recriada na ação de um corpo nômade que se aterra no território em ação de desterritorialização, ou seja, na potencia, na Zona de Experiência. Lançar um corpo cotidiano na fronteira é, portanto, lançá-lo no nomadismo, ou seja, na ação ativa de possibilidades. Não corpos dóceis (Foucault), mas corpos potentes. Não corpos passivos, mas ativos. É nesse sentido que a fronteira e o corpo nômade estão no campo da política e da ética [...]. (p. 5)

Esse comprometimento se dá, portanto, em ritmos outros, em variações e em posicionamentos éticos perante a vida e o trabalho. São modos de habitar os territórios das práticas em saúde e, sobretudo, modos de conceber o que são e do que são feitos os encontros na clínica. E são, também, antes de qualquer coisa, estados de corpo com vontade de criação.

Trajetos singulares em improvisações diárias de gestar a clínica nas relações consigo e com o outro. Processos de trabalho em saúde e processos de trabalho na/da vida.

\section{Colaboradores}

Os autores participaram igualmente da discussão dos resultados, da revisão e aprovação da versão final do artigo.

\section{Referências}

1. Bondía JL. Notas sobre a experiência e o saber de experiência. Rev Bras Educ. 2002; 19:20-8.

2. Campos MRB. Recordar, repetir, criar: intensidades pulsionais na obra de Pina Bausch. São Paulo [Internet]. São Paulo: Institituto Sedes Sapientae; 2011 [citado 22 Mar 2016]. Disponível em: http://www.ip.usp.br/laboratorios/lapa/versaoportugues/2c71a.pdf

3. Cassiano $M$, Furlan R. O processo de subjetivação segundo a esquizoanálise. Rev Psicol Soc. $2013 ; 25(2): 373-8$.

4. Ferracini R. Fronteiras, paradoxos e micropercepções. In: Artes cênicas sem fronteiras. São Paulo: Anarco; 2007.

5. Lancetti A. A clínica peripatética. São Paulo: Hucitec; 2006.

6. Fox N. The ethics and politics of caring: postmodern reflections. London: Health, Medicine and Society; 2014.

7. Merhy EE. Os CAPS e seus trabalhadores: no olho do furacão antimanicomial. Alegria e alívio como dispositivos analisadores. In: Merhy EE, Amaral H, organizadores. Reforma psiquiátrica no cotidiano II. São Paulo: Hucitec; 2004. cap. 8, p. 55-66.

8. Thomé AM. Os centros de atenção psicossocial como dispositivos de atenção à crise: em defesa de certa (in)felicidade inventiva. In: $2^{\circ}$ Colóquio internacional do NUPSI: construções de felicidade. 2013; São Paulo [Internet]. São Paulo: Núcleo de Psicopatologia, Políticas Públicas de Saúde Mental e Ações Comunicativas em Saúde Pública; 2013 [citado 22 Mar 2016]. p. 4. Disponível em: http://nupsi.org/coloquios/coloquio-internacionalnupsi-usp-invencoes-democraticas-construcoes-da-felicidade/ 
9. Merhy EE. Enfrentar a lógica do processo de trabalho em saúde: um ensaio sobre a micropolítica do trabalho vivo em ato, no cuidado. In: Carvalho SR, Ferigato $S$, Barros $M E$, organizadores. Conexões: saúde coletiva e políticas de subjetividade. São Paulo: Hucitec; 2009. p. 276-300.

10. Moehlecke V. Ballet contágio: tecnologias da arte e da imagem [tese]. Porto Alegre: Universidade Federal do Rio Grande do Sul; 2011.

11. Deleuze G. Conversações. Rio de Janeiro: Editora 34; 1992.

12. Passos E, Benevides B. Passagens da clínica. In: Maciel A, Kupermann MD, Tedesco S, organizadores. Polifonias: clínica, política e criação. Rio de Janeiro: Conreacapa; 2006. p. 88-100.

13. Passos E, Barros RB. Complexidade, transdisciplinaridade e produção de subjetividade. In: Fonseca TMG, Kirst PG, organizadores. Cartografias e devires. A construção do presente. Porto Alegre: UFRGS; 2003. p. 81-9. 
O presente artigo discute uma experiência prática desenvolvida em um CAPS, onde buscou-se, a partir de uma intervenção grupal com os usuários, explorar a experimentação do corpo em movimento. Abordando aspectos do trabalho cotidiano de um Serviço de Saúde Mental, propõe uma estratégia de cuidado de si e do outro a partir da re-invenção da prática clínica permeada por recursos artísticos e, particularmente, da dança. Discute, ainda, a gestão do tempo como moduladora de modos de operar dos trabalhadores e usuários, afirmando a aposta na prática da dança como dispositivo que permite um contratempo ao ritmo acelerado do serviço; como um espaço de estar entre, de acompanhar e tornar possíveis corpos mais receptivos aos encontros e às composições como premissa de uma clínica inventiva que se almeja construir.

Palavras-chave: Dança. Clínica. Centro de Atenção Psicossocial.

\section{From anxieties to movement: a Psychosocial Care Center (CAPS), the clinic and a dance}

The paper presents a practical experience that was developed in a CAPS, which sought to explore experimenting with the body in movement by means of group work with patients. The intervention addresses aspects of the day-to-day work of a Brazilian mental health service and proposes a strategy for care of both oneself and of the other, based on the reinvention of clinical practice to include artistic resources, with a particular emphasis on dance. The authors discuss time management as a modus operandi for staff and patients, showing that investing in dance serves as a tool to counteract the hurried pace of the service. It also serves as a space to be among, to accompany and to make it possible for bodies to be more receptive to encounters and to dance compositions, as the basis for a more inventive clinical space that they intend to develop.

Keywords: Dance. Clinic. Psychosocial Care Center.

De las inquietudes al movimiento: un Centro de Atención Psicosocial (CAPS), la clínica y una danza

El presente artículo discute una experiencia práctica desarrollada en un CAPS, en la cual se buscó, a partir de una intervención grupal con los usuarios, explorar la experimentación del cuerpo en movimiento. Abordando aspectos del trabajo cotidiano de un Servicio de Salud Mental, propone una estrategia de cuidado de sí mismo y del otro a partir de la reinvención de la práctica clínica impregnada de recursos artísticos y particularmente de la danza. También se discute la gestión del tiempo como moduladora de modos de operar de los trabajadores y usuarios, afirmando la apuesta en la práctica de la danza como un dispositivo que permite un contratiempo al ritmo acelerado del servicio. Como un espacio de estar entre, de acompañar y hacer posibles cuerpos más receptivos a los encuentros y a las composiciones como premisa de una clínica inventiva que se anhela construir.

Palabras clave: Danza. Clínica. Centro de Atención Psicosocial. 